\title{
VARIABILIDAD EN LA ESTRUCTURA MORFOLÓGICA DE LOS SUSTANTIVOS ESPAÑOLES
}

\section{VARIABILITY IN THE MORPHOLOGICAL STRUCTURE OF SPANISH NOUNS}


Las propuestas formuladas en torno a la formación de diminutivos, la asignación del acento, la formación del plural y las llamadas marcas de palabra en el ámbito de la morfología nominal del español remiten en último término a la estructura morfológica de los sustantivos españoles. Los estudios más relevantes en torno a esta última tienen un enfoque fonológico (cf. Harris, 1983, Roca, 1989, Baković, 2014, entre otros) o morfológico (cf. Hooper y Terrell, 1976, Harris, 1991, 1992, Bermúdez-Otero, 2006, 2007 y Bonet, 2006, entre otros), dependiendo de la naturaleza de los criterios en los que basan sus generalizaciones. Intentamos mostrar que los análisis propuestos en estos estudios tienden a poner en tela de juicio cualquier caracterización de los segmentos finales de las formas nominales basada en rasgos propiamente morfológicos, en contradicción con propuestas como las de Lloret (2013), Melčuk (2013) y Roca y Feliú (2002). Por otro lado, algunos datos ponen de manifiesto que, en uno o diversos procesos morfológicos, formas idénticas en sus segmentos finales y su patrón acentual se pueden comportar de manera diferente, asemejarse en su comportamiento formas dispares en sus segmentos finales y su patrón acentual, e incluso presentar un sustantivo dado un comportamiento diferente.

Datos de este tipo muestran las limitaciones de las propuestas que acabamos de mencionar y, sobre todo, la importancia de la variabilidad estructural de los sustantivos españoles para su representación morfológica. Esa variabilidad motiva el intento de integrar en cierta medida, reinterpretándolas, las aportaciones de esas propuestas. A este efecto, examinamos las fuentes de la variabilidad que se observa en las formas nominales del español antes de estudiar su alcance, el estatus y las funciones de los segmentos vocálicos (pre)finales, así como las implicaciones de nuestras observaciones que, según intentamos mostrar, dan pie a una representación morfológica más sistemática y consistente de los sustantivos españoles.

Palabras Clave: sustantivos españoles, esquema flexivo, representación morfológica, estructura flexiva, prosodia léxica

The proposals formulated about diminutive formation, stress assignment, plural formation and the so-called word markers in the domain of Spanish nominal morphology refer ultimately to the morphological structure of the Spanish nouns. The most relevant studies have a phonological (Harris 1983, Roca 1989, Baković 2014, among others) or morphological basis (Hooper and Terrell 1976, Harris 1991, 1992, Bermúdez-Otero 2006, 2007 and Bonet 2006, among others), depending on the nature of the criteria on which their generalizations are based. We try to show that the analyzes proposed in these studies tend to call into question any characterization of the final segments of the nominal forms based on properly morphological traits, in contradiction with proposals such as Lloret (2013), Melčuk (2013) and Roca and Feliú (2002). On the other hand, some data show that, in one or several morphological processes, forms identical in their final segments and their accentual patterns may behave differently, whereas forms differing in their final segments and their accentual patterns may show the same 
behavior in such processes and, moreover, a single noun may behave differently in the same conditions.

Data of the latter type show the limitations of the proposals just mentioned and, above all, the importance of the structural variability of the Spanish nouns for their morphological representation. This variability motivates the attempt to integrate to a certain extent, reinterpreting them, the contributions of these proposals. To this end, we examine the sources of variability observed in Spanish nominal forms before studying their scope, as well as the status and functions of the(pre) final vowels, and the implications of our observations which, as we intend to show, motivate a more systematic and consistent morphological representation of Spanish nouns.

KEYWORDS: Spanish nouns, inflectional schema, morphological representation, inflectional structure, word prosody

FECHA DE RECEPCIÓN: 07/12/2015

FECHA DE ACEPTACIÓN: 12/01/2016 



\section{VARIABILIDAD EN LA ESTRUCTURA MORFOLÓGICA DE LOS SUSTANTIVOS ESPAÑOLES}

\section{VARIABILITY IN THE MORPHOLOGICAL STRUCTURE OF SPANISH NOUNS}

Théophile Ambadiang Universidad Autónoma de Madrid

\section{Introducción}

A pesar de que las numerosas propuestas formuladas a lo largo de las últimas décadas en torno a la asignación del acento, la formación del plural y las llamadas marcas de palabra tratan, en último término, de la estructura morfológica de los sustantivos españoles, no acaban de converger en un análisis de esta última que dé cuenta de manera consistente y cabal a la vez del estatus y de las funciones de los segmentos finales, sobre todo vocálicos, de las formas nominales (Meľčuk, 2013). Mientras que los análisis de corte fonológico estudian la correlación que puede existir entre los patrones acentuales típicos de las formas nominales y constituyentes tales como la raíz o la palabra y, por consiguiente, estudian la estructura de esas formas solo de manera indirecta (Baković, 2016; Roca, 1989), en el caso de las propuestas basadas en consideraciones morfológicas 
destacan dos grandes orientaciones. Por un lado, el interés se ha centrado esencialmente en los segmentos finales de palabra y sus funciones, particularmente en el caso de los segmentos vocálicos que actúan como cierre morfológico en las formas del singular. Generalizaciones características de este tipo de enfoque se pueden ver en trabajos en los que las vocales finales de las formas nominales tienen una función meramente clasificatoria, al limitarse el análisis a los aspectos formales tanto de estos segmentos como de las formas en que aparecen (cf. Harris, 1991, 1992, entre otros), o bien están asociados a los rasgos de género de estas últimas (cf. Lloret, 2013; Lloret y Viaplana, 1998). Por otro, se privilegia la variación que se produce en el comportamiento de los sustantivos en procesos morfológicos tales como la formación de diminutivos. En este caso, se parte de la idea según la cual existe cierta correlación entre las divergencias que se observan en dicho comportamiento y las diferencias que se producen en la estructura morfológica de los sustantivos. A modo de ejemplo, Bermúdez-Otero (2006, 2007) contrapone las formas nominales que llama pseudoplurales a otras que caracteriza como atemáticas y temáticas, a la luz de su comportamiento en el marco de la formación de diminutivos.

Las limitaciones de las propuestas de corte morfológico, reseñadas en diferentes partes de este trabajo, tienen que ver en parte con el hecho de que no pueden evitar que (i) sustantivos idénticos en cuanto a sus segmentos finales y su patrón acentual se comporten de manera diferente en uno o diferentes procesos morfológicos, (ii) nombres disímiles en sus segmentos finales y su patrón acentual se comporten 
de manera idéntica en tales procesos. A las incongruencias implícitas en estas dos observaciones cabe añadir que, en algunos casos, una misma forma puede presentar comportamientos diferentes en un mismo proceso o en diferentes procesos morfológicos.

Intentamos mostrar que existe cierta correlación entre estas observaciones, en el sentido de que las divergencias y coincidencias implícitas en (i) y (ii) no se pueden disociar de la variabilidad que puede afectar a una misma forma nominal. Más aún, el estudio de esta última tiene implicaciones de cierto interés para la representación morfológica de los nombres españoles, en buena medida porque permite integrar los enfoques de corte morfológico que acabamos de reseñar, además de resaltar la importancia que entrañan a este respecto tanto la prosodia como los rasgos de los segmentos vocálicos (pre)finales. A este fin, examinamos a continuación las fuentes de la variabilidad que se produce en las formas nominales del español, así como sus implicaciones para la representación morfológica de los sustantivos españoles en los apartados siguientes. A modo de cierre, recalcamos la necesidad de ahondar tanto en la caracterización morfológica de los segmentos finales de las formas nominales como en la incidencia que puedan tener en el comportamiento de estas últimas en diversos procesos morfológicos, en el supuesto de que este último es lo que motiva en definitiva la interpretación que puedan recibir esas formas desde el punto de vista de su estructura morfológica. 


\section{Las fuentes de la variabilidad estructural de los sustantivos españoles}

Con independencia de su enfoque, uno de los cometidos de los estudios en torno a la morfología de los sustantivos españoles es dar cuenta de la incidencia que tienen los factores de naturaleza morfológica, sintáctica y prosódica en la estructura de estos últimos y, sobre todo, del papel de los segmentos finales de palabra, particularmente los vocálicos. La complejidad de los efectos que tienen estos factores se manifiesta en parte en la disparidad que se observa entre las caracterizaciones que han recibido estos últimos. A modo de ejemplo, análisis en los que segmentos finales del tipo descrito por algunos estudiosos como marcas de palabra son caracterizados como "the last morpheme before the inflectional plural suffix" (cf. Baković, 2016) coinciden solo en parte con otros que resaltan el carácter átono de este tipo de segmento o de la sílaba que encabeza (cf. Harris, 1983; Roca, 1990, 2006). De acuerdo con una descripción del tipo que propone Baković (en prensa), por ejemplo, en caso de ir inmediatamente seguidos de la desinencia del plural $-s$, los segmentos vocálicos tónicos serían marcas de palabra (cf. bantús, cafés, capós, jabalís, mamás, sofás) y, por consiguiente, se caracterizarían del mismo modo que las vocales átonas prefinales, tengan estas últimas carácter léxico (cf. niños, niñas, libros, libras) o no (cf. cárceles, papeles, redes, soles, etc.), mientras que desde un punto de vista fonológico, el carácter tónico de un segmento sería precisamente lo que impide que funcione como marca de palabra o desinencia (cf. bantú-es, jabalí-es). En contraste con segmentos de este último 
tipo, los segmentos átonos (pre)finales han sido caracterizados como extramétricos, es decir, como elementos fónicos finales de palabra que quedan fuera del dominio prosódico asociado a las piezas léxicas (Harris, 1983, 1991, 1992), o bien como unidades fónicas que quedan fuera de la raíz, al coincidir la linde derecha de esta última con la sílaba tónica de la palabra (Roca, 1988; Baković, 2016). Obsérvese, con todo, que descripciones de este tipo no suelen incluir constituyentes incontrovertidamente morfológicos que, como es el caso con algunos sufijos derivativos vocálicos, además de ser tónicos, van inmediatamente seguidos de la desinencia de plural. Este sería el caso, por ejemplo, con el sufijo derivativo -í que, al ser tónico formaría parte de la raíz de la forma derivada, mientras que por su posición sería, de acuerdo con la caracterización de Baković (2016), por ejemplo, una desinencia en algunas ocasiones (cf. ceut-í-s, irak-ís), pero no así en otras (ceutí-e-s, irakí-e-s).

Coincidencias y divergencias como las que acabamos de señalar entre los sustantivos españoles están estrechamente ligadas a la variabilidad que se observa en el comportamiento de muchos de ellos, además de reflejar los efectos que tiene la interacción de los factores fonológicos, morfológicos y sintácticos en su estructura $y$, por consiguiente, dan una idea de la importancia que tienen para la representación de estos últimos. En esta sección estudiamos la incidencia de los factores fonológicos, morfológicos y morfofonológicos. Intentamos mostrar el modo en que dan cuenta de las diferencias que se producen entre los sustantivos españoles desde el punto de vista de su variabilidad estructural, además de explicar la disparidad que se observa en la caracterización 
de los segmentos finales. En un primer momento examinaremos la estructura morfológica de las formas nominales a la luz de las caracterizaciones que han recibido sus segmentos finales, tomando como referencia el esquema flexivo de las formas no verbales del español (cf. Ambadiang, 1993, 1997, 2011, 2015). Luego cotejaremos la estructura morfológica típica de los sustantivos con los dominios prosódicos asociados a estos últimos.

\subsection{La morfofonología de los segmentos finales $y$ el concepto de esquema flexivo}

En las caracterizaciones de los segmentos finales de palabra reseñadas antes prevalecen factores de naturaleza fonológica y morfológica. En el primer caso, lo que determina si un segmento final es una marca de palabra o no tiene que ver con su rasgo de tonicidad o, al menos en algunos análisis (Harris, 1992; Bermúdez-Otero, 2006, 2007; Bonet, 2006), con los rasgos fonéticos que lo conforman. En el segundo, prima la función de estos segmentos en tanto que terminaciones "depositarias de información genérica" que, de acuerdo con esta caracterización de la RAE-ASALE (2009: 90: $\$ 2.3 \mathrm{c}$ ), subsume no solo la existencia de un determinado tipo de relación entre un segmento dado y alguno de los rasgos de género típicos del español, sino también una determinada distribución de ese segmento dentro de la forma nominal. Desde el punto de vista de la relación que, en la gramática del español, se produce entre la fonología y la morfología, las implicaciones de esta doble caracterización plantean diversos problemas que dificultan una visión de 
conjunto de la flexión nominal en esta lengua. Por un lado, en una descripción basada en criterios funcionales, los nombres españoles se dividirían en dos sub-grupos diferentes conformados, respectivamente, por sustantivos cuyos segmentos finales son marcas de género o bien marcas de palabras. Por otro, las marcas de género no dejan de constituir un subconjunto de las llamadas marcas de palabras, en el sentido de que, además de ser segmentos vocálicos (pre)finales, cumplen el requisito de la atonicidad. Como se puede observar, ninguna de estas generalizaciones permite por sí sola caracterizar todos los segmentos vocálicos (pre)finales de los sustantivos españoles. Así, de usarse el concepto de marca de palabra en referencia a todos estos segmentos, se perdería de vista la asociación que se produce entre algunos de ellos y los rasgos de género (como ocurre en las propuestas de Harris, por ejemplo), mientras que aplicar el de marca de género en las mismas condiciones supondría admitir que diferentes segmentos (pre)finales están asociados con cada uno de los rasgos de género (como propone Lloret, 2013), lo que implicaría una relación de alomorfia indiscriminada, y por tanto problemática y de escaso interés desde un punto de vista teórico (Harris, 1991, 1992). Retomamos esta cuestión en la sección 4.

En términos más generales, la correlación que en descripciones de este tipo se produce entre el carácter átono de un segmento vocálico por un lado y, por otro, su distribución y su función como marca de género o como marca de palabra sugiere la existencia entre los factores fonológicos y morfológicos de una doble relación de necesidad, en el sentido de que caracterizaciones morfológicas parecen sub- 
yacer a generalizaciones fonológicas, mientras que características fonológicas tales como la tonicidad parecen necesarias a la hora de determinar si un segmento puede o no ser una marca de palabra en un sustantivo dado. Es lo que ponen de manifiesto correlaciones como la que se establece entre la (a)tonicidad de un segmento y su estatus en tanto que desinencia. Más aún, en la medida en que análisis de este tipo no incluyen los segmentos vocálicos tónicos (pre) finales, no pueden dar cuenta de plurales bastante frecuentes como cafés, capós, jabalís, mamás y sofás. Formas de este último tipo sugieren que, en contra de lo que dan a suponer estos análisis, no hay una relación de necesidad entre la tonicidad de un segmento fonológico y su distribución, que puede ajustarse o no a su estatus y su función.

$\mathrm{Si}$, como sugieren las observaciones aducidas en el párrafo anterior, no existe un paralelismo estricto entre las diversas caracterizaciones que pueden recibir los segmentos (pre)finales de palabra, cabe preguntarse acerca del modo en que se interrelacionan estas últimas. Para intentar contestar a este interrogante, nos basaremos en las formas de plural de los sustantivos, es decir, en piezas léxicas en las que el segmento - $s$, además de ser el exponente canónico del plural, ocupa una posición (canónica) que le permite actuar como cierre morfológico, para lo cual debe estar precedido de una vocal átona cuya presencia puede tener una motivación léxica (cf. mano, mapa), morfológica (cf. niño/niña, naranja/naranjo) o fonológica (cf. redes, soles). Esto es lo que ocurre con los plurales que se pueden caracterizar como regulares, pero no así en otros casos en los que el segmento -s no ocupa la posición canónica de la marca de número (cafés, 
compás, inglés, vals, items, mamuts, etc.), o bien no marca de manera específica el plural (cf. atlas, cosmos, virus, etc.); (cf. Ambadiang, 2015). En ausencia de esta consonante final, segmentos vocálicos léxica o morfológicamente especificados actúan como cierre morfológico en las formas de singular de muchos sustantivos españoles. El interés de las formas de plural estriba en que, en contraste con las de singular, muestran un paralelismo estructural muy marcado, con independencia de que tengan una forma singular o no, y cualquiera que sea la configuración de esta última. En los plurales regulares, una vocal léxicamente especificada o no precede inmediatamente a un segmento consonántico que hace de cierre morfológico (cf. libr-o-s, niñ-a-s, capitan-e-s, papel-e-s, sol-e-s, etc.). La recurrencia de este patrón estructural, que se observa incluso en formas cuya vocal prefinal es tónica (caf-é-s, sof-á-s, etc.), en sustantivos cuyos plurales presentan cierta variación estructural (cf. esqu-í-s/esquí-es) y en formas invariables del tipo de atlas, cosmos y virus, motiva un esquema flexivo del tipo que presentamos en (1), que daría cuenta de la estructura flexiva de los sustantivos españoles y, de manera más específica, del carácter desinencial de los segmentos último y penúltimo de todas las formas que se prestan a una interpretación plural, en paralelo con los plurales en -es.

(1) Esquema flexivo de las formas nominales

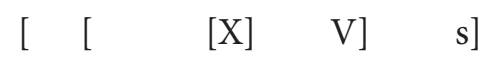

Nuestra propuesta se basa en la idea de que /s/ es un segmento que tiene una función morfológica en tanto que mar- 
ca de número. Como tal, este segmento ocupa el margen derecho de cualquier forma nominal plural y está separado de la raíz (X) por una vocal ('V'), que ocupa la casilla que correspondería a la marca de género en aquellos sustantivos que llevan lo que llamaremos más abajo una marca canónica o genuina de género, además de actuar como cierre en las formas de singular. Al igual que la asociación que se produce entre los segmentos prefinal y final de un sustantivo dado y las casillas finales del esquema flexivo no está necesariamente determinada por consideraciones de naturaleza prosódica, la estructura flexiva de un sustantivo no está necesariamente determinada por su prosodia. En este sentido, cabría hablar de una autonomía relativa de la morfología respecto de la fonología. La interacción de informaciones típicas de ambos componentes es posible en piezas léxicas dotadas de características morfológicas (en contraste con adverbios simples, preposiciones, etc.), como ponen de manifiesto formas (derivadas o no) del tipo de inglés o cafés, en las que el efecto conjunto de la presencia de $-s$ y la acentuación oxítona varía, en términos estructurales, dependiendo del rasgo de número que afecta a cada una de estas formas.

La observación según la cual los sustantivos plurales acaban de manera característica en una secuencia - $V s$ tiene dos tipos de implicaciones. Por una parte, motiva el paralelismo que hemos señalado antes entre los sustantivos que se prestan a una interpretación plural, puesto que, desde el punto de vista de su configuración, no parece haber diferencias entre formas nominales plurales tanto simples (cf. niños, niñas, tribus, metrópolis) como derivadas (cf. compras, costes, naranjos) y formas que, como atlas, cosmos, lunes, 
tesis y virus, no responden a ninguna de las caracterizaciones anteriores. A pesar de que estas clases de sustantivos presentan diferencias interesantes sobre las que volvemos más abajo, se asemejan estos últimos en que acaban todos en una secuencia - Vs que, además de ser el cierre típico de las formas de plural, permite una segmentación del tipo que sugerimos en (2). En este sentido, cabe decir que todas esas formas presentan una misma estructura flexiva.

(2) Estructura flexiva de los sustantivos españoles

\begin{tabular}{|c|c|c|}
\hline $\begin{array}{ll}\text { a. } & {[[[\text { niñ }] \text { o }] \mathrm{s}]} \\
& [[\text { compr }] \mathrm{a}] \mathrm{s}]\end{array}$ & $\begin{array}{ll}\text { c. } & {[[[\operatorname{cosm}] \mathrm{o}] \mathrm{s}]} \\
& {[[[\mathrm{atl}] \mathrm{a}] \mathrm{s}]}\end{array}$ & $\begin{array}{ll}\text { e. } & {[[[\mathrm{pi}] \mathrm{e}] \mathrm{s}]} \\
& {[[[\mathrm{caf}] \mathrm{e}] \mathrm{s}]}\end{array}$ \\
\hline $\begin{aligned} \text { b. } & {[[[\text { trib }] \mathrm{u}] \mathrm{s}] } \\
& {[[[\text { clas }] \mathrm{e}] \mathrm{s}] } \\
& {[[[\operatorname{tax}] \mathrm{i}] \mathrm{s}] }\end{aligned}$ & $\begin{aligned} \text { d. } & {[[[[\text { vir }] \mathrm{u}] \mathrm{s}]} \\
& {[[\text { lun }] \mathrm{e}] \mathrm{s}] } \\
& {[[[\text { tes }] \mathrm{i}] \mathrm{s}] }\end{aligned}$ & $\begin{aligned} \text { f. } & {[[[\text { bantú] e] s] }} \\
& {[[[\text { esquí] e] s] }}\end{aligned}$ \\
\hline
\end{tabular}

Por otra parte, hemos sugerido que la adjunción del segmento $-s$ no tiene más consecuencias que las propiamente morfológicas, en lo que se asemejaría a las vocales (Hooper y Terrell, 1976), pero no así a secuencias más complejas del tipo de -es, -esa, -ina, o -isa, usadas para marcar el número plural (cf. bantú-es, esquí-es, papel-es, regímen-es) o el género femenino (cf. abad-esa, gall-ina, poet-isa), cuya adjunción implica generalmente el desplazamiento del acento hacia la derecha. Otra característica común a estos sonidos tiene que ver con el hecho de que si bien aparecen con una fre-

\footnotetext{
${ }^{1}$ Bermúdez-Otero (2007) asocia el segmento /e/ de una palabra como caudales a una posición o casilla 'Th' que corresponde al constituyente temático o vocal temática (stem formative).
} 
cuencia mucho mayor en sustantivos paroxítonos o llanos, también lo hacen en formas nominales oxítonas o agudas e incluso proparoxítonas o esdrújulas, algo que no ocurre con los otros segmentos, a excepción de /n/, como observamos en (3), donde /r/ y /l/ se incluyen a efectos de comparación.

\section{(3) Acento prosódico en correlación con segmentos finales de palabra}

\begin{tabular}{|l|l|l|l|l|l|}
\hline & Vocal & $/ \mathrm{s} /$ & $/ \mathrm{n} /$ & $/ \mathrm{r} /$ & $/ \mathrm{l} /$ \\
\hline oxítono: & mamá & compás & rehén & color & fusil \\
\hline paroxítono: & mama & atlas & virgen & prócer & cárcel \\
\hline proparoxítono: & anémona & éxtasis & régimen & Júpiter & ?? \\
\hline
\end{tabular}

Como señalan diversos estudios (cf. Hooper y Terrell, 1976, entre otros), la acentuación paroxítona es el patrón no marcado en sustantivos acabados en vocal, /s/ y /n/, y la oxítona en sustantivos que acaban en cualquiera de las consonantes restantes. ${ }^{2}$

Por otro lado, si bien las vocales son, de lejos, los segmentos finales con los que se producen más variantes acen-

\footnotetext{
${ }^{2}$ Las diferencias entre formas marcadas y no marcadas desde el punto de vista del acento quedan reflejadas en estas observaciones de Bello (1859: 35): "Señálase el acento [...] con la señal que aparece sobre las letras que representan las vocales agudas de estas dicciones, cárcel, alelí, barómetro, pelícano. Pero no es costumbre señalar siempre el acento; sino sólo cuando se aparta de las analogías o reglas generales de la lengua. Señálase, por ejemplo, en las dicciones cárcel, alelí, porque en castellano [el acento] carga más a menudo sobre la última vocal, cuando la dicción termina en consonante, y sobre una vocal de la penúltima sílaba, cuando la dicción termina en vocal; que es cabalmente lo contrario de lo que sucede en esas dos palabras. Y lo señalamos en barómetro y pelícano porque lo más común es que las dicciones castellanas se acentúen sobre la última o la penúltima sílaba”. Véase Alcoba (2013) para una discusión detallada de la acentuación marcada.
} 
tuales, existen también voces de doble acentuación acabadas en $/ \mathrm{s} /, / \mathrm{n} / \mathrm{y}$, en menor medida, $/ \mathrm{r} / \mathrm{y} / \mathrm{l} /$, en contraposición con lo que ocurre con el resto de consonantes. Variantes de este tipo se presentan en pares como los ejemplificados en (4), donde la forma más usual en cada caso es el primer miembro de cada par.

(4) Variantes acentuales nominales

\begin{tabular}{|l|l|l|l|l|l|}
\hline & Vocal & $/ \mathrm{s} /$ & $/ \mathrm{n} /$ & $\mathrm{r} /$ & $/ \mathrm{l} /$ \\
\hline $\begin{array}{l}\text { llano/ } \\
\text { agudo }\end{array}$ & acné/acne & & $\begin{array}{l}\text { cercén/ } \\
\text { cercen }\end{array}$ & $\begin{array}{l}\text { beréber/ } \\
\text { bereber }\end{array}$ & $\begin{array}{l}\text { misil/ } \\
\text { mísil }\end{array}$ \\
\hline $\begin{array}{l}\text { llano/ } \\
\text { esdrújulo }\end{array}$ & icono/ícono & $\begin{array}{l}\text { ósmosis/ } \\
\text { osmosis }\end{array}$ & $\begin{array}{l}\text { bádminton/ } \\
\text { badminton }\end{array}$ & & \\
\hline $\begin{array}{l}\text { agudo/ } \\
\text { esdrújulo }\end{array}$ & $\begin{array}{l}\text { dominó/ } \\
\text { dómino }\end{array}$ & & & & \\
\hline
\end{tabular}

Como se puede ver, las vocales son los únicos segmentos finales que ocurren en variantes de formas nominales que presentan todos los patrones acentuales típicos del español. En contraste con esta distribución, resultan llamativas las restricciones que se observan con las variantes en que está implicado el segmento /s/, cuyo alcance queda limitado al par llano/esdrújulo. Nótese a este respecto que la diferente ubicación del acento en los miembros de los pares incluidos en (4) no implica diferencias en cuanto a su esquema flexivo cuando acaban en vocal, como pone de manifiesto la manera en que forman sus plurales (cf. acn-é-s/acn-e-s, icon-o-s/ ícon-o-s, domin-ó-s/domin-o-s), salvo en el caso de sustantivos cuyas formas de singular acaban en /i/ o en /u/ tónica (cf. bantú-es, esquí-es) y que, de acuerdo con la presente 
descripción, se comportan como los singulares acabados en consonante, a diferencia de variantes del tipo de bant-ú-s y esqu-í-s. Con los nombres acabados en /s/, la validez de esta observación queda restringida al par llano/esdrújulo, es decir, precisamente a aquellas formas en las que las diferencias prosódicas no dan pie a diferentes esquemas flexivos (cf. osmos-is/ósmos-is). En el resto de casos se producirían diferencias como las observadas en pares del tipo de ingles/ inglés, cuyos miembros difieren en su rasgo de número y, en el ámbito de algunas variedades dialectales, en variantes plurales como cafés/cafeses, manís/manies/manises o maravedís/maravedíes/maravedises. El hecho de que el cotejo de tales formas con un esquema como el de (1) arroje resultados diferentes (cf. el contraste de man-í-s y maní-e-s) sugiere que las restricciones observadas en la variación prosódica de las formas acabadas en $-s$ tienen implicaciones de naturaleza morfológica, a diferencia de lo que ocurre con otros segmentos del tipo de /l/ y /r/, cuyas limitaciones distribucionales parecen tener que ver con la escasez de formas nominales acabadas en estos segmentos $y$, por tanto, asociadas a aquellas casillas que se han dejado en blanco en la tabla. ${ }^{3}$

Las observaciones aducidas en este epígrafe sugieren que las particularidades de /s/ y, sobre todo, el contraste con los otros segmentos consonánticos a excepción de $/ \mathrm{n} /$, resultan difíciles de explicar si no se tiene en cuenta su papel en la morfología flexiva del español, sea nominal o verbal.

\footnotetext{
${ }^{3}$ Este mismo comportamiento de /s/ se observa en la flexión verbal, ámbito en el marco del cual se asemeja al del segmento $/ \mathrm{n} /$, en contraposición con otros segmentos implicados en la flexión verbal del tipo de /d/ o /r/. Volvemos sobre esta especificidad más abajo (sección 4).
} 
En ese carácter desinencial se asemeja este segmento a las vocales finales de las formas de singular. Esta caracterización da pie, por otro lado, para replantear tanto la relación que existe entre la estructura morfológica de los sustantivos españoles y la prosodia léxica como los efectos de su interacción, en caso de producirse esta última. En este sentido, una descripción formal de la estructura de los sustantivos españoles debe dar cuenta de todas las clases de sustantivos señaladas antes, así como de las variantes características de muchos de ellos.

\subsection{Estructura morfológica y dominio prosódico}

Las múltiples disparidades que se producen en la caracterización fonológica y morfológica de los segmentos vocálicos (pre)finales de los sustantivos españoles y entre las secuencias $-V s$ finales contrastan fuertemente con el paralelismo que se observa en cuanto a su distribución, si tomamos como referencia un esquema como el que proponemos en (1). Como ya hemos señalado, las vocales que preceden a la desinencia de plural o al segmento de cierre que comparte casilla con ella tienen la misma distribución, a pesar de que solo un subconjunto de ellas se puede caracterizar como marcas de género semejantes, desde un punto de vista funcional, a secuencias del tipo de -esa, -ina o -isa. Por otro lado, la uniformidad observada en variantes del plural del tipo de acn-é-s/acn-e-s pone de manifiesto que las diferencias de carácter acentual no implican necesariamente divergencias en la distribución de los segmentos tónicos y átonos implicados. Con todo, esta uniformidad no se produce en 
todos los casos puesto que, como ya se ha señalado, muchas formas de singular requieren la adjunción de una secuencia - es en lugar del segmento/s/, cuyo efecto es la presencia en la palabra resultante de una nueva sílaba que, en algunos casos, provoca un desplazamiento del acento a la derecha que permite mantener la restricción relativa a la ventana de las tres sílabas en las formas nominales (Harris, 1983; Roca, 1988, 2006). El desplazamiento del acento que se produce, por ejemplo, en formas como regímenes resulta difícil de explicar si no se tiene en cuenta la presencia de la secuencia - es en que acaban, lo que no parece consistente con la idea de que secuencias finales de este tipo no intervienen en el proceso por medio del cual se determina el patrón acentual de tales formas. A la vista de los efectos que, desde un punto de vista prosódico, tiene la adjunción de tales secuencias a formas de singular del tipo de régimen, resulta problemático un análisis de acuerdo con el cual la extrametricidad sería una característica tanto de los segmentos vocálicos finales como de secuencias - Vs finales, puesto que la necesidad de evitar las estructuras sobreesdrújulas resultantes de la adjunción de estas últimas es precisamente lo que motiva el desplazamiento del acento hacia la derecha.

Por otro lado, la acentuación tiene una incidencia remarcable solo en relación con la estructura flexiva de aquellos sustantivos que pueden ajustarse de diversas maneras al esquema flexivo de (1), dependiendo precisamente de su patrón acentual, es decir, en un número relativamente reducido de casos (formas acabadas en $-s$ o en una vocal aguda tónica). Tanto el carácter marginal de los efectos de la acentuación como la observación anterior relativa a la in- 
cidencia de la morfología en la acentuación sugieren, por un lado, que la morfología tiene cierta autonomía respecto de la prosodia. Por otro, indican que la incidencia de esta última en tanto que factor implicado en la caracterización morfológica de las formas nominales resulta limitada, como muestra el papel de elemento de cierre de $-s$ en sustantivos cuyas formas de singular acaban en vocal (cf. cafés, cafres, niños, papás, papas) y en formas nominales invariables que acaban en una secuencia - $V s$ átona (cf. atlas, cosmos, crisis, lunes, virus), en marcado contraste con los casos en que un sustantivo singular acabado en una secuencia - $V s$, cuya vocal es tónica (cf. compás, francés), se ajusta a un esquema del tipo de (1) en su forma de plural (cf. compas-e-s, frances-e-s).

De acuerdo con estas observaciones, la morfología determina la asignación del acento, en el sentido de que el dominio prosódico que corresponde a una forma nominal no se puede establecer sin tener en cuenta rasgos morfológicos como el de número, es decir, los efectos formales de procesos tales como la formación del plural, mientras que la prosodia incide en la morfología nominal esencialmente en la distinción de las estructuras flexivas que pueden presentar nombres cuya configuración segmental resulta idéntica (cf. ingles: ingles/inglés). En este sentido, un esquema como el propuesto en (1) subyace a lo que podríamos definir como una regla de buena formación desde el punto de vista de la flexión nominal, cuando no se identifica a ella. Rellenando el esquema de derecha a izquierda, es decir empezando por $/ \mathrm{s} /$, cabe establecer la distribución de los diferentes elementos que constituyen las formas nominales. Tenemos, por tanto, dos clases de estructuras autónomas, morfológica 
y prosódica, que determinan conjuntamente la estructura de las formas nominales en los términos que acabamos de especificar. Con todo, un esquema del tipo propuesto en (1) no agota las interpretaciones a las que las formas nominales del español se pueden prestar desde el punto de vista de su configuración o estructura morfológica, como intentamos mostrar en la próxima sección.

\section{Alcance de la variabilidad}

El esquema de (1) pone de manifiesto el marcado paralelismo estructural que existe entre los sustantivos españoles susceptibles de tener una interpretación plural. Sin embargo, no da cuenta de la variación que se observa desde el punto de vista de la representación morfológica de estos últimos, debido a que factores muy diversos inciden en la variabilidad que se observa en la morfología nominal del español. En esta sección, consideramos los efectos de tales factores, particularmente la naturaleza de los segmentos prefinales y finales, su patrón acentual, así como - en el caso de la formación de diminutivos- la extensión del sustantivo considerado en cada caso.

\subsection{Estructura flexiva y representación morfológica}

Partimos de la hipótesis según la cual los sustantivos españoles pueden recibir diversas representaciones, dependiendo del modo en que los elementos que los conforman quedan asociados al esquema de (1), así como de la manera 
en que esos sustantivos se comportan en diversos procesos derivativos. Desde este punto de vista, una primera distinción se puede establecer entre los plurales regulares y otros tipos de formaciones que, aun siendo susceptibles de una interpretación plural, entrañan diversos grados de desviación en comparación con aquellos. Entre estas últimas, cabe distinguir las siguientes, que se pueden caracterizar como plurales irregulares (cf. Ambadiang, 2015).

\section{(5) Plurales irregulares}

(i) formas que, siendo plurales, no presentan una vocal inmediatamente antes de la marca de número (cf. items, mamuts, robots, tics, tótems, etc.)

(ii) formas que, siendo plurales, presentan una vocal acentuada inmediatamente antes de la marca de número (cf. bantús, cafés, manís, etc.)

(iii) nombres invariables (análisis, ángelus, atlas, bocazas, brindis, Carlos, diabetes, Mercedes, virus, etc.)

Las formas incluidas en (5) coinciden en que se produce un desajuste entre su material fonológico y morfológico y la información morfológica asociada a ellas. Ambos tipos de información son necesarios a la hora de determinar la estructura flexiva de cualquier forma nominal, como ponen de manifiesto pares del tipo de inglés/ingles por un lado y, por otro, de inglés/cafés y cafés/ingles. Debido a que diferentes informaciones morfológicas están presentes en los miembros del segundo par, estos últimos van a tener es- 
tructuras flexivas distintas, en el sentido de que su material fonológico se va a asociar de manera diferente al esquema de (1), a pesar de su semejanza segmental y prosódica. Al contrario, el hecho de que los miembros del último par compartan las mismas informaciones morfológicas determina que tengan un esquema flexivo idéntico a pesar de presentar diferentes patrones acentuales. Por último, los miembros del primer par presentan diferencias en sus rasgos morfológicos y en su patrón acentual. Debido al ajuste que se produce entre ambas clases de informaciones, estas diferencias determinan de manera conjunta las divergencias observadas en el esquema flexivo de las formas implicadas en ese par. En la sección 2 hemos intentado mostrar el interés que nociones tales como las de 'estructura flexiva' y 'esquema flexivo' pueden tener para el análisis de la flexión nominal del español. En la presente sección intentamos dar cuenta del hecho de que los sustantivos españoles pueden diferir o presentar variaciones no solo en la manera en que su material fonológico y morfológico se asocia con (1), sino también en el comportamiento que presentan en procesos morfológicos diferentes de la formación del plural. A modo de ejemplo, formas nominales del tipo de lectora, señora y motora coinciden tanto en las informaciones morfológicas que expresan como en su patrón acentual y tienen un mismo esquema flexivo, al asociarse de manera idéntica a (1) su material fonológico y morfológico. Esta coincidencia no evita, sin embargo, que se comporten de manera diferente en la formación de diminutivos, como muestran sus derivados respectivos, a saber lectorcita, señorita y motorita. Sugerimos que tales diferencias están estrechamente ligadas 
al hecho de que estas bases derivativas se prestan a representaciones morfológicas distintas. Así, en la medida en que el diminutivo de lectora se asemeja al de lector (cf. ${ }^{*}$ lectorita), cabe pensar que estas dos bases comparten estructura o que se analiza aquella por analogía a esta, a diferencia de lo que ocurre con las otras dos bases que no están implicadas en una relación de este tipo (en el caso de motora) o, de estarlo, actuarían como base derivativa, como muestra el contraste entre la forma diminutiva masculina señorito y la que sería de esperar de ser señor la base derivativa, a saber ${ }^{*}$ señorcito. ${ }^{4}$ Las observaciones que siguen dan una idea del alcance de la variación que se produce en la formación de los diminutivos de las clases de formas ejemplificadas en (5).

Las bases de (5i) y (5ii) se asemejan en que no sufren ningún tipo de cambio en los procesos morfológicos en los que están implicadas, pero seleccionan diferentes sufijos diminutivos: las formas de (5ii) se combinan con un único alomorfo del sufijo diminutivo, a saber -cito, en contraste con la heterogeneidad que se produce con las de (5i). Cabe, asimismo, proponer una única caracterización para ambas clases de formas en el sentido de que en todas ellas la casilla que precede a la marca de plural está vacía (item-s, bantú-s, mamut-s), si bien la vocal léxicamente especificada en las formas de (5ii) puede servir para rellenarla (cf. bant-ú-s, esqu-ís), siendo la inserción de la vocal subespecificada /e/ propia de algunas formas como bantú-e-s, esquí-e-s.

\footnotetext{
${ }^{4}$ Harris (1994) procede de manera análoga cuando asocia la diferencia que señala entre formas diminutivas del tipo lloroncita y lloronita a diferencias que existen entre las bases derivativas desde el punto de vista de la estructura morfológica.
} 
En el caso de los nombres invariables, tienen valor discriminatorio tanto la extensión del sustantivo, es decir el número de las sílabas que lo conforman, como la naturaleza de su segmento vocálico prefinal. Por otra parte, a diferencia de las formas de (5i) y (5ii), los nombres invariables tienen la casilla prefinal llena y, en este sentido, sus constituyentes quedan asociados de la misma manera que los de los plurales regulares al esquema de (1), si bien difieren de estos últimos en la formación de diminutivos. Así, las bases bisilábicas se comportan de manera diferente dependiendo del segmento vocálico que presenten en posición prefinal. Aquellas que presentan /a/ o bien /o/ en esta posición se combinan con el alomorfo -ito que bien podría funcionar como interfijo, al igual que ocurre con los plurales regulares cuyas formas de singular presentan /a/ y /o/ en esa posición (cf. atl-itas, Carl-itos, etc.). Por su parte, las que presentan /e, $\mathrm{i}, \mathrm{u}$ / en posición prefinal seleccionan otras variantes sufijales en las que la marca de plural no queda reflejada y, dependiendo de la vocal o de la forma considerada, sufren o no cambios en su configuración (cf. lun-ecito, cris-ecita, brindis-ito, virus-ito, etc.). Por último, el factor de la extensión opone las bases acabadas tanto en -os y -as como en -us, que proceden de una única manera con independencia de su extensión, a las acabadas en -is y en -es, cuyo comportamiento difiere dependiendo de su extensión. Si bien todas las bases de este último tipo pierden la secuencia - $V s$ final, las bases bisilábicas seleccionan el alomorfo -ecito (cf. cris-ecita, lunecito) mientras que las de más de dos sílabas se combinan con-ito (cf. analis-ito, Merced-itas, Socrat-ito, etc.). 
Variaciones del mismo tipo se observan también con bases idénticas en sus segmentos finales y su patrón acentual en procesos en los que se combinan, por ejemplo, con determinados sufijos para formar nombres o adjetivos relativos a gentilicios. Es lo que ocurre con bases como Panamá o Canadá, que pierden su vocal final en tales procesos (cf. panam-eño, canad-iense), al igual que las bases cuya vocal final es átona (cf. angol-eño, malagu-eño, etc.), en contraste con otras como Alcalá, que no pierden su vocal final en el mismo contexto (cf. alcala-eño). El cotejo de estas formas derivadas con otras en las que están implicados otros sufijos como -íno (cf. alcala-íno, bilba-íno, vizca-íno, etc.) sugiere que en estas diferencias confluyen requisitos característicos de los sufijos implicados y propiedades de las bases derivativas que tienen que ver con una mayor o menor facilidad en lo que concierne el borrado de su vocal (pre)final, así como las condiciones en torno a su uso. Así, sufijos del tipo de -eño pueden admitir o no la presencia de una vocal final tónica en la base derivativa, a diferencia de otros como -íno, por ejemplo, con los que esa vocal se mantiene. En términos más generales, con ambos tipos de sufijos se produce el borrado de la vocal final átona de la base derivativa. Sin embargo, el resultado es de manera característica una raíz acabada en consonante en el caso de -eño (cf. marfil-eño, angoleño, andujar-eño, guayaquil-eño) -y también de -iense (cf. liliput-iense, etc.) - , frente a la heterogeneidad formal de las raíces que se combinan con -ino. Estas últimas pueden acabar en vocal (cf. alcala-íno, vizca-íno, etc.), en consonante (salamanqu-ino), pudiendo además tener la base carácter supletivo, como en derivados del tipo de neoyorqu-ino o en 
dobletes del tipo de salamanqu-ino/salmant-ino. ${ }^{5}$ El hecho de que bases del tipo de Panamá pierdan su vocal acentuada en procesos derivativos en los que se les adjunta un sufijo como -eño, pero no así en caso de adjuntárseles otros sufijos como -ito (cf. panama-cito (sombrero)), mientras que otras como Alcalá no lo hacen, muestra que bases idénticas en sus segmentos finales y su patrón acentual se pueden comportar de manera diversa, dependiendo del proceso en que están implicadas o, en términos más precisos, del afijo que se les adjunta, aparte factores relativos a su uso. ${ }^{6}$ Esta misma variación se puede observar también con una misma base al combinarse con diferentes sufijos derivativos. Es lo que muestran las diferencias observadas entre formas derivadas del tipo de tribal/tribucita y espiritual/espiritismo, en las que, dependiendo del sufijo que se le adjunte, la base derivativa pierde o no su vocal final.

Las observaciones aducidas en los párrafos anteriores sugieren por una parte que el proceso de borrado - que, por lo demás, se produce incluso con formas desprovistas de estructura morfológica y, por consiguiente, de un constituyente temático, como sería el caso con numerales del tipo de treinta y cuarenta (cf. treint-ena, cuarent-ena, cuarent-ón, etc.),- no aporta una información relevante acerca de la estructura o la representación morfológica de las formas

\footnotetext{
${ }^{5}$ Ambadiang (2011) asocia el borrado de las vocales y secuencias - Vs finales de palabra a la naturaleza de los segmentos implicados en cada caso; cf. Montermini (2011) para un análisis similar de las vocales finales en italiano.

${ }^{6}$ Baković (2016: nota 5) sugiere que en el caso de formas como panameño, el segmento /a/ final de la base Panamá es reanalizado como una marca de palabra en contexto de afijación derivativa.
} 
nominales ni de la tendencia del sufijo a amalgamarse con la base y del grado en que la vocal (pre)final es susceptible de ser borrada, es decir de la menor o mayor facilidad con que es borrada. Por otra parte, ponen de manifiesto que ambos tipos de representaciones son necesarios para dar cuenta de las coincidencias y divergencias que se observan entre las formas nominales del español, en la medida en que las relaciones que contraen (o su interacción) sirven para explicar los desajustes y la variación que se producen en el comportamiento de muchas de ellas desde un punto de vista morfofonológico, según intentamos mostrar en la próxima sección.

En términos generales, divergencias como las que acabamos de señalar dan pie para distinguir las bases de acuerdo con el ajuste que permiten entre los dos tipos de representaciones que hemos propuesto, a saber la estructura flexiva y la representación morfológica propiamente dicha. De acuerdo con nuestras observaciones, el primero está motivado en la noción de esquema flexivo, mientras que el segundo resulta de un proceso de interpretación en el que está implicado de diversas maneras aquel. El mayor ajuste se produce en el caso de los plurales o pseudoplurales acabados en una secuencia - $V s$ cuya vocal es - $a$ o bien - $o$, y el menor con las formas acabadas en -es y en -is. De acuerdo con las observaciones aducidas en esta sección, los sustantivos españoles se pueden prestar a diferentes caracterizaciones estructurales, en el sentido de que presentan variantes morfológicas dependiendo del proceso en que estén implicados. En este sentido, es necesaria una caracterización de las formas nominales que tenga en cuenta tanto sus coincidencias 
como aquellos aspectos en que difieren. Las convergencias más significativas están asociadas al paralelismo o simetría estructural que se produce entre las formas nominales que hemos caracterizado antes como morfológicamente completas. Hemos asociado esa simetría a lo que hemos llamado esquema flexivo nominal, una estructura abstracta que da cuenta de la interpretación que recibe una palabra completamente flexionada, es decir, en su forma de plural y, más allá, de la coincidencia estructural que se produce entre los plurales regulares y los otros tipos de formas que, debido a su configuración segmental y su acentuación, no pueden recibir una marca de plural. En la medida en que la uniformidad de comportamiento observada en la flexión de número no se produce necesariamente en los procesos derivativos, conviene dar cuenta separadamente de ambas situaciones antes de estudiar las correlaciones que puedan existir entre ellas.

Sugerimos, por consiguiente, que la interpretación de la estructura morfológica de las formas nominales es susceptible de cierta variabilidad y que esta última resulta más constreñida en el ámbito de la morfología flexiva que en la morfología derivativa (cf. (6)). Como se ha señalado antes, el esquema flexivo de (1), en tanto que condición de buena formación desde el punto de vista de la morfología flexiva, sirve de referencia para todos los sustantivos, y da cuenta de la uniformidad que se observa en el modo en que sus segmentos finales, con independencia de su función concreta y su estatus, quedan asociados a las casillas a las que hemos asignado funciones desinenciales. La consistencia de esta generalización, válida incluso para aquellos sustantivos que, como tabú y colibrí admiten plurales alternativos en -es 
(cf. tabú-es y colibrí-es), se manifiesta en el carácter cada vez más marginal de estos últimos. En el ámbito de la morfología derivativa, los afijos divergen en cuanto a la forma de las bases a las que se adjuntan y, por consiguiente, a su estructura. La selección puede basarse en factores tales como la extensión de la base (algunos procesos, como la formación de diminutivos, distinguen las palabras mínimas de otros tipos de estructuras), o bien el carácter supletivo de la base, como hemos observado antes con -íno, la naturaleza de la vocal o secuencia $-V s$ final de la base, según ponen de manifiesto las diferencias observadas entre formas derivadas del tipo de tribal/tribucita, espiritual/espiritismo, etc., el carácter átono o tónico de la vocal final de la base, como en contrastes del tipo ejemplificado en alcala-íno/bilba-íno. Desde un punto de vista morfofonológico, el resultado de la combinación de un sufijo dado con una base depende, por consiguiente, tanto de requisitos típicos de dicho sufijo en lo que se refiere al borrado de la vocal final de la base (lo que, para algunos, tiene que ver con la tendencia del sufijo a amalgamarse con la base; cf. Montermini, 2011, por ejemplo), como de la mayor o menor resistencia del segmento final o de los segmentos finales respecto del proceso de borrado. Ambadiang (2011) sugiere a este respecto una escala que refleja la tendencia al borrado característica de los segmentos finales de las formas nominales $y$, por tanto, de la variabilidad que se produce en la estructura de estas últimas. En esa escala, la tendencia a la variación es muy consistente con los segmentos vocálicos altos $/ \mathrm{i} /, / \mathrm{u} /$, con los que el proceso de borrado se aplica con poca sistematicidad, y más si van seguidos de /s/. Es menor con /e/ y -es y escasa o nula con el resto de vocales, con las 
que el borrado se produce de manera sistemática. La uniformidad observada en la formación de los plurales no se puede disociar de la interpretación de la configuración de las formas nominales en función del esquema flexivo presentado en (1), mientras que las diferencias observadas en el comportamiento de las bases derivativas están estrechamente ligadas a las restricciones que imponen los afijos que se les adjuntan y al grado en que sus segmentos finales se prestan al proceso de borrado o a los efectos de este último sobre ellos.

\section{2. ¿Representación morfológica en ausencia de una estructura flexiva?}

Una propuesta como la que acabamos de esbozar se caracteriza por el hecho de que descansa en lo que es, en último término, una doble representación de las formas nominales. Desde este punto de vista, otras propuestas implican un único nivel o tipo de representación. Este es el caso, por ejemplo, con el análisis propuesto por Bermúdez-Otero (2006, 2007) que, a efectos de comparación, reseñamos brevemente a continuación. Bermúdez-Otero distribuye los sustantivos españoles en tres grandes clases que incluyen, respectivamente, formas atemáticas, temáticas y pseudoplurales. Las formas temáticas se caracterizan porque acaban en algún segmento temático del tipo de /-o/, /-a/, /-\{e, 0$\} /$ y/-e/, cuya función - la buena formación de las formas en las que aparecen - es meramente formal, a diferencia de las formas atemáticas, que no presentan un constituyente de este tipo. Esta clasificación queda refrendada, según este estudioso, 
por el comportamiento que presentan estas clases de sustantivos en la formación de diminutivos. Las formas derivadas a partir de las bases atemáticas conservan todos los segmentos que conforman estas últimas y, en el caso más específico de las formas invariables, se mantiene el segmento /s/ final de la base ante el sufijo derivativo (cf. brindis-ito, virus-ito). En los derivados obtenidos a partir de las bases temáticas, por el contrario, ese segmento y la vocal anterior a él resultan borrados (cf. cris-ecita). Por otra parte, en contraste con pseudoplurales del tipo tanto de crisis como de Carlos y Sócrates, las formas atemáticas presentan de manera característica dos alomorfos cuya selección está determinada morfológicamente. A modo de ejemplo, alomorfos del tipo de virus y brindis son seleccionados en las formas simples de los sustantivos correspondientes, así como en sus diminutivos (cf. virusito, brindisito), y los alomorfos vir- y brind- en el resto de derivados (cf. viral, vírico, brindar, etc.).

Una descripción del tipo que propone Bermúdez-Otero plantea diversos problemas que solo podemos comentar brevemente aquí. El primero tiene que ver con la relación de alomorfia establecida entre las variantes alomórficas típicas de los pseudoplurales y, más específicamente, con la correlación que se produce entre su estatus en la gramática del español y su distribución y frecuencia. En el caso de virus, por ejemplo, vir- tiene una frecuencia mayor y una distribución más variada que el otro alomorfo y, sin embargo, no parece presentar otras características consideradas típicas de lo que sería una variante básica. En el mismo sentido, este tipo de descripción tiende a perder de vista el paralelismo estructural que existe entre bases del tipo de brindis y 
crisis, acabadas en los mismos tipos de segmentos o secuencias de segmentos y con el mismo patrón acentual. Por otra parte, el borrado de /s/ en bases del tipo de crisis y análisis al que alude Bermúdez-Otero tiene el efecto de dar pie a temas - como crisi y análisi- de difícil encaje en su análisis, en parte porque el segmento final /i/ no está incluido en la lista de vocales que desempeñan el papel de constituyente temático o vocal temática. Esta última observación induce, a su vez, a replantear otra de las hipótesis de Bermúdez-Otero, de acuerdo con la cual en la formación de diminutivos se adjuntan sufijos a temas (no a raíces, ni nombres o palabras completas), a la luz de la observación que hace acerca de /s/ final, al señalar que "if the final /s/ does not appear before the suffix in evaluative derivatives, the noun is pseudoplural and the /s/ is a plural marker, lying outside the stem". En este último caso, cabría entender que la pieza léxica implicada en la derivación no es un tema, sino una palabra que luego pierde su segmento final /s/ (o bien la secuencia - Vs final), con la problemática consecuencia señalada antes.

Las observaciones aducidas en esta sección sugieren que los procesos morfológicos implicados en el análisis de Bermúdez-Otero entrañan una complejidad mayor de la que la clasificación que propone puede dar cuenta, como sugieren los numerosos interrogantes que se siguen de esta última. A modo de ejemplo, resulta difícil de entender la disparidad de comportamiento que se observa en la formación de diminutivos en el caso de las bases que describe como temáticas, puesto que, de acuerdo con la caracterización que hace de ellas, presentan la misma estructura. En este sentido, da cuenta solo en parte de un subconjunto de los 
datos que se propone analizar. En términos más generales, las coincidencias y divergencias que se producen en el comportamiento de las formas nominales en diversos procesos morfológicos no pueden recibir una explicación consistente y cabal sobre la base exclusiva de clases de formas nominales como las establecidas en los análisis de Bermúdez-Otero (2006), Bonet (2006) y los anteriores de Harris (1991, 1992), es decir, en cualquier análisis que no tenga en cuenta las implicaciones de un esquema como el propuesto en (1). ${ }^{7}$

Sugerimos, a la luz de la discusión anterior, que el valor diagnóstico de la formación de diminutivos en que se basa el análisis de Bermúdez-Otero concierne más aspectos de la estructura de las formas nominales de los considerados en sus trabajos, al tiempo que entraña una consistencia menor de lo que sugieren dichos trabajos. Esto último se debe a que (i) el propio sufijo diminutivo presenta diferentes variantes, (ii) las bases que selecciona cada una de las variantes afijales se caracterizan por una marcada heterogeneidad desde un punto de vista segmental y prosódico y (iii) existe una relativa opacidad en la forma de muchos diminutivos respecto de sus bases respectivas. Por un lado, cada una de las variantes del afijo diminutivo se adjunta a bases cuyos rasgos fonológicos, morfofonológicos y morfológicos distan

\footnotetext{
${ }^{7}$ Otros interrogantes tienen que ver con el hecho de que mientras que algunas bases temáticas pierden su vocal final al adjuntárseles un sufijo diminutivo (cf. man-ita), la adjunción de la variante larga de este sufijo a otras bases lleva consigo lo que es en último término la inserción de un segmento /e/ que haría de vocal temática (cf. flor-ecita, sol-ecito). Otro tanto ocurre con el solapamiento parcial que se produce entre dos de sus clases temáticas, caracterizadas, respectivamente, como temas en $\{\mathrm{e}, 0\} / \mathrm{y}$ los temas en /e/. Volvemos sobre aspectos de la clasificación de Bermúdez-Otero en la sección 4.
} 
de ser idénticos y, por consiguiente, bases diferentes en su estructura morfológica, como lector y lectora, forman sus diminutivos de manera similar (cf. lector-cito/lector-cita), mientras que otras idénticas en sus segmentos y su patrón prosódico, como brindis y crisis, seleccionan sin embargo variantes diferentes del afijo diminutivo, además de diferir en su comportamiento (la secuencia - Vs final queda borrada en crisis, pero no así en brindis (cf. cris-ecita/brindisito)); (cf. Ambadiang, 1997 y Lázaro Mora, 1999 para una descripción más detallada).

Más allá de las propuestas de Bermúdez-Otero, las limitaciones del valor diagnóstico de la formación de diminutivos no se pueden disociar de la variabilidad estructural de las propias formas nominales, a la que la formación de diminutivos es especialmente sensible, como muestran, por una parte, las coincidencias que se producen entre los diminutivos de bases como lectora o pastora y, por otra, las diferencias que se observan con bases del tipo de lectores o pastores y con pseudoplurales como Sócrates. Hemos intentado mostrar que una manera de paliar esta insuficiencia consiste en observar el comportamiento que presentan de manera característica las formas nominales en diversos procesos morfológicos y, más específicamente, a la luz de los dos tipos de representaciones señalados antes. Solo de este modo cabe dar cuenta de la interpretación morfológica que reciben esas formas sobre la base del efecto conjunto de factores tales como la acentuación del sustantivo considerado, la naturaleza de su segmento vocálico prefinal y la presencia de un segmento /s/ final, como intentamos mostrar en la próxima sección. Por consiguiente, en respuesta 
a la pregunta que encabeza el último apartado de esta sección, resulta difícil proceder a una representación morfológica de las formas nominales en ausencia de una caracterización basada en el concepto de esquema flexivo, es decir, si no son interpretadas como piezas léxicas flexionadas. ${ }^{8}$

\section{Implicaciones para la representación morfológica de los sustantivos españoles}

Hasta ahora nuestras observaciones se han centrado en las características morfofonológicas y la distribución de los segmentos vocálicos y consonánticos prefinales y finales de las formas nominales. Según hemos visto, la disparidad morfofonológica de esos segmentos contrasta fuertemente con la uniformidad de su distribución. En esta sección consideraremos el estatus teórico de estos segmentos y las relaciones que contraen, antes de examinar las implicaciones de nuestra descripción para la representación de las formas nominales y el estudio de la flexión nominal en general.

\section{1. ¿Homonimia o multifuncionalidad de los segmentos vocálicos (pre)finales?}

Si bien muchos estudiosos recalcan la importancia de los segmentos vocálicos (pre)finales para el análisis de la flexión nominal, las múltiples divergencias que se observan

\footnotetext{
${ }^{8}$ Las críticas de Mel'čuk (2013: 713-715) a Harris (1991) tienen implicaciones parecidas a las subsumidas en esta conclusión; cf. también Roca (1989) y Ambadiang (1999).
} 
en las generalizaciones formuladas en torno a ellos ponen de manifiesto el escaso consenso que existe en torno a su estatus téorico y sus propiedades morfológicas (cf. Mel'čuk, 2013 para un estado de la cuestión reciente). Así, limitándonos de momento a los estudios que proponen una caracterización formal de los segmentos vocálicos, descripciones como las propuestas en Bermúdez-Otero (2006) y Bonet (2006) coinciden solo en parte. Incluyen en sendos grupos o clases las formas nominales acabadas en /o/ y /a/. Con el resto de sustantivos, Bonet distingue un grupo de formas acabadas en /e/ de otro que incluye formas acabadas en - 0 , descritas como "words ending in a consonant or a stressed vowel" (2006: 314). Por su parte, la descripción de Bermúdez-Otero distingue cuatro clases de temas acabados, respectivamente, en /-o/, /-a/, /-\{e, 0 \}/ y /-e/. De acuerdo con la descripción de Bonet, todas las formas nominales de singular presentan alguna de las cuatro terminaciones ya señaladas, a saber /o, a, e, $0 / \mathrm{y}$, por consiguiente, no existen formas nominales atemáticas, a diferencia de lo que sugiere el análisis de Bermúdez-Otero.

Aparte el hecho de que ambas descripciones no parecen incluir las formas que presentan una vocal alta en posición prefinal ni dan cuenta de ellas, interesa subrayar que las clases temáticas basadas en los segmentos vocálicos finales de las piezas léxicas no diferencian las formas nominales simples de las derivadas, al limitarse las observaciones a la similitud formal de sus segmentos finales. Ello queda particularmente claro en la siguiente observación de Bonet: “[...] the class marker $-e$ is typical of many deverbal nouns [..] (less often other deverbal nouns are formed with the class marker 
$-a[.$.$] , or the class marker -o[.]$.$) . This word-formation pro-$ cess is very productive in Spanish" (2006: 319).

En contraste con lo que sugiere este tipo de descripción, estos segmentos tienen diversas funciones y motivaciones, en correlación con los ámbitos en los que actúan dentro del sistema lingüístico. Por consiguiente, contraen una relación de hominimia. A modo de ejemplo, /a/ y /o/ están asociados a rasgos de género en niña y niño, mientras que resultan de una especificación léxica en mapa y mano, además de estar implicados en procesos derivativos en pares del tipo de naranja/naranjo y en formas tales como compra y engaño. En el caso de /e/ ocurre otro tanto en pares del tipo de jefe/jefa y en formas derivadas como corte, mientras que su presencia en los plurales en -es resulta de un proceso de epéntesis. ${ }^{9}$ El hecho de que estas diferencias no implican divergencias en el comportamiento de estos segmentos desde un punto de vista morfofonológico parece favorecer la indistinción que caracteriza el tratamiento implícito en los análisis de Bermúdez-Otero y Bonet y, sobre todo, la tendencia a reducir su caracterización a sus aspectos formales.

Obsérvese, con todo, que esta caracterización, en la que está implícita la idea de la multifuncionalidad de estos segmentos, no es la única que se puede formular en relación con su funcionamiento (cf. Mel'čuk, 2013 para una discusión más detallada). En efecto, las diferencias señaladas

\footnotetext{
${ }^{9}$ Una descripción de este tipo descarta generalizaciones, como las que propone Mel’čuk, uno de cuyos efectos es la equiparación de pares tales como hermano/ hermana, naranja/naranjo cuyos miembros contraen, en opinión de este estudioso, una relación derivativa, a pesar de caracterizar /o, a, e, 0/ como alomorfos sufijales que marcan el género (2013: 745).
} 
antes entre los segmentos que representamos por medio de /a/, /o/ y /e/ no solo ponen en tela de juicio la tendencia a asociarlos a una etiqueta única del tipo de 'marca de palabra' o 'desinencia', por ejemplo; también sugiere que el borrado de estos segmentos no depende de su estatus como constituyente temático o como constituyente nominal, marca flexiva o sufijo derivativo, sino de su posición respecto de determinados sufijos derivativos iniciados en vocal, como ponen de manifiesto formas del tipo de treintena, cuarentena, cuarentón, etc. derivadas a partir de bases desprovistas por definición de vocales temáticas (cf. treinta, cuarenta, cincuenta). Dicho de otro modo, el borrado de estos segmentos depende de requisitos típicos de cada sufijo: se produce con la inmensa mayoría de sufijos, con la salvedad de unos pocos como -avo e -ismo/-ista (cf. Pensado, 1999: 4461-4462). Por consiguiente, a pesar de las diferencias que se producen entre ellos desde un punto de vista funcional, estos segmentos presentan un comportamiento morfofonológico similar, uno de cuyos efectos, como ya se ha observado, es difuminar su relación de hominimia.

\subsection{Las relaciones de los segmentos vocálicos (pre)finales y su estatus teórico}

A diferencia de Bermúdez-Otero (2006) y Bonet (2006), cuyos análisis se limitan a los aspectos formales de las vocales (pre)finales de los sustantivos, es decir, a su caracterización como constituyentes temáticos y como marcas de palabra, respectivamente, Lloret (2013) y Mel’čuk (2013) consideran que tales segmentos tienen carácter gramatical, 
al estar asociados con los rasgos de género. De acuerdo con la descripción de Lloret (2013), centrada en una variedad dialectal del catalán, los sustantivos quedan distribuidos en dos grupos. Los nombres masculinos o de clase I se caracterizan porque terminan en /o, e, w/ y 0 , mientras que los nombres femeninos o de clase II acaban típicamente en /a/ y 0 . Dos rasgos de este análisis resultan especialmente llamativos. Por un lado, los segmentos asociados a cada rasgo de género contraen una relación de alomorfia en la cual el primer elemento de cada serie es el alomorfo prioritario o no marcado, en contraste con otros, secundarios y terciarios que resultan, respectivamente, de procesos fonológicos y de algún tipo de especificación léxica. Por otro, ambas series comparten uno de los alomorfos, a saber 0 . Al no tener una motivación morfofonológica, la relación que contraen estos segmentos no se puede disociar del hecho de que coinciden en marcar un mismo rasgo de género en cada caso. Aplicada a la flexión nominal española, una descripción de este tipo da pie a una alomorfia masiva entre los exponentes de ambos rasgos de género, puesto que muchos de los segmentos finales de las formas de singular, a saber, /o, a, e/ y 0 , pueden marcar cualquiera de estos rasgos, algo que ocurre también en la descripción que propone Mel'čuk (2013). Ya hemos señalado que tal relación resulta problemática para el análisis de la flexión nominal, además de entrañar un interés teórico escaso. A continuación intentamos constreñir el alcance de esa relación en la flexión de género del español.

De acuerdo con las observaciones aducidas en el epígrafe anterior, de existir una relación de alomorfia en los términos de la descripción de Lloret (2013), quedaría limitada 
a aquellos segmentos cuya función es exclusivamente la de marcar el rasgo de género. Desde este punto de vista, no estarían implicados en una relación de este tipo los segmentos vocálicos que tienen funciones de sufijos derivativos, al estar asociados de forma exclusiva con sustantivos femeninos en el caso de /a/ y masculinos en el caso de /o/, /e/. En el caso de la vocal /e/, cabría diferenciar, además, un segmento cuya distribución queda limitada a ciertos contextos morfofonológicos de otro que sí tiene una mayor libertad distribucional típica de las marcas de género. Solo este último puede competir con /a/ y /o/ en tanto que marca de género. Una vez admitida esta competición de los tres segmentos, la pregunta que sigue es la de saber qué relación contraen. En caso de ser alomórfica, tal relación tendría carácter supletivo, puesto que no cabe obtener o derivar ninguno de estos segmentos a partir de ninguno de los segmentos restantes. Con todo, una relación supletiva de este tipo plantea problemas para el análisis, debido en parte a la escasez de series supletivas tan extensas como la que resultaría de una descripción de este tipo, como se ha señalado antes. En ausencia de una relación de alomorfia, la variación observada en el alcance de cada uno de estos segmentos en la flexión nominal da pie para asociar los segmentos vocálicos /a/ y /o/ a los rasgos de género masculino y femenino. A diferencia de /e/ que actúa como cierre morfológico de sustantivos singulares tanto masculinos como femeninos, además de tener en ocasiones una motivación morfofonológica, /o/ aparece en la inmensa mayoría de los sustantivos masculinos y /a/ en los sustantivos femeninos. Una descripción de este tipo tiene la ventaja de evitar la relación de suplencia a la que aludíamos antes, 
al tiempo que permite discriminar estos segmentos desde el punto de vista de su estatus como marcas de género: /a/ y /o/ serían las marcas regulares o canónicas de los rasgos de género masculino y femenino, respectivamente, mientras que la presencia de /e/ en un sustantivo singular, al igual que la de /i/ y /u/, indicaría irregularidad en lo que se refiere a la flexión de género.

Diferentes hechos parecen confirmar el estatus morfológico de los segmentos /a/ y /o/. Por una parte tienen un uso muy frecuente tanto en la flexión nominal como en la verbal. Por otra, actúan como cierre morfológico en cualquier forma diminutiva, formando a veces una secuencia $-V s$ con un segmento final /s/. Asimismo, su presencia en bases del tipo de atlas, paraguas, Carlos y Milagros, por ejemplo, es lo que determina el comportamiento que caracteriza estas últimas en un proceso como la formación de diminutivos (cf. atl-itas, Carl-itos), frente a otras bases del tipo de brindis, crisis, lunes, virus, etc., cuyo comportamiento resulta menos uniforme. Por último, /a/ y /o/ son borrados de manera general en los diversos procesos derivativos típicos del español, incluso cuando, según hemos visto antes, llevan acento, sobre todo en el caso de /a/ (cf. canad -iense, panam-eño).

\subsection{Canonicidad y representación morfológica}

Las observaciones aducidas en estas páginas sugieren que el comportamiento de los segmentos (pre)finales de palabra está estrechamente ligado al concepto de canonicidad. Este último se puede referir tanto a la naturaleza de estos 
segmentos como a su distribución. En términos formales, los segmentos /o/ y /a/ son las marcas canónicas de los dos rasgos de género tanto en los sustantivos (cuyo género es inherente) como en aquellas formas desprovistas de una vocal prefinal léxicamente especificada que concuerdan con ellos, en contraste con /e, i, u/, según se ha señalado antes. Desde un punto de vista distribucional, estos segmentos se oponen a cualquier vocal tónica inmediatamente anterior a una consonante /s/ que actúa como cierre morfológico. En lo que se refiere más específicamente a este último segmento, el factor decisivo tiene que ver con su distribución, es decir, que su estatus depende tanto de la naturaleza de la vocal que le precede como de su acentuación. Así, la presencia de un segmento átono /o/ o bien /a/ delante de un segmento /s/ final favorece la interpretación de este último como marca de plural en todos los procesos morfológicos típicos del español y, por consiguiente, da cuenta del paralelismo que se produce entre la estructura flexiva de formas como atlas, cosmos, niños, niñas, paraguas, etc., y la representación que reciben en procesos morfológicos diferentes de la formación del plural: dicho paralelismo se refleja en el hecho de que la secuencia -os o - as final resulta borrada en todos los procesos derivativos. Se produce, por contra, una marcada disparidad con los sustantivos cuyo segmento (pre)final es cualquiera de las otras vocales del español. Así, la secuencia - Vs final que se mantiene en la formación de los diminutivos de bases que presentan un segmento /u/ prefinal es borada sin embargo ante sufijos derivativos iniciados en vocal (cf. viral). El resto de secuencias - Vs finales resultan borradas en las mismas condiciones en todos los procesos deriva- 
tivos y, además, en el caso de la formación de diminutivos, el factor de la extensión discrimina las bases de dos o más sílabas. El comportamiento de las bases de dos sílabas acabadas en /e(s)/ (cf. clas-ecita y lun-ecito, por ejemplo) y, con excepciones, en /is/ (cris-ecita frente a brindis-ito) no difiere del de los monosílabos (cf. flor-ecita, sol-ecito), en contraste con las bases de más de dos sílabas, que se combinan con la variante no marcada del sufijo diminutivo (cf. analis-ito, Merced-itas). Si bien - Vs tiene la misma distribución en lunes, crisis y virus por un lado y, por el otro, en atlas y cosmos, da pie a representaciones morfológicas diferentes en la formación de diminutivos (cf. /lun-/, /cris-/, /virus/), pero no así en el resto de procesos derivativos, en los que esta secuencia resulta borrada. En otras palabras, las secuencias /is/ y /es/ finales son borradas en todos los procesos derivativos y, además, las formas en las que aparecen son interpretadas en la formación de diminutivos como desprovistas de desinencias; de ahí /lun-/, /cris-/, etc. Las formas de singular acabadas en /a, o, e/ se comportan de la misma manera que las bases acabadas, respectivamente, en -as, -os y -es, en contraste con las acabadas en /i/ y /u/, cuyo comportamiento entraña una mayor variabilidad. Las que presentan /i/ en posición final mantienen esta vocal en sus diminutivos y demás derivados, mientras que el comportamiento de las bases acabadas en $/ \mathrm{u} /$ resulta más variable: se observa una marcada tendencia al mantenimiento de la vocal final tanto en sus diminutivos (cf. tribu-cita/trib-ita) como en los otros derivados (cf. espiritual/espiritismo, impetuoso, etc.). Por último, el carácter tónico de la vocal prefinal no favorece la interpretación de /s/ final como marca de plural, al no tener 
este último segmento la distribución canónica típica de la desinencia de número, según indican dobles plurales como cafeses y variantes del tipo de manís, manies, manises. Como se puede observar, en este último caso, a lo que es una única representación en el ámbito de la morfología derivativa, a saber /maní/ le corresponden diversas estructuras flexivas: /man-í(s)/, /maní-(e-s)/.

De acuerdo con las observaciones anteriores, cabe concebir la representación morfológica de las formas nominales en función de la canonicidad de sus segmentos prefinales y finales. En este sentido, solo las bases que presentan secuencias finales del tipo de -as y -os tienen el mismo comportamiento en todos los procesos morfológicos, al igual que las bases acabadas en -es y en -is que, además, son las únicas con las que tiene relevancia el factor de la extensión en la formación de diminutivos. Las formas nominales acabadas en -us, por el contrario, sufren modificaciones en la mayoría de los procesos, pero no en todos. Una ilustración de las correlaciones que se producen entre los dos tipos de representación subsumidos en la descripción que hemos llevado a cabo se puede ver en (6), donde la estructura flexiva de las formas consideradas viene indicada en negrita. 
(6) Variabilidad en la morfología nominal

\begin{tabular}{|c|c|c|c|c|}
\hline & \multirow{2}{*}{$\begin{array}{l}\text { Formación } \\
\text { del plural }\end{array}$} & \multicolumn{2}{|c|}{ Formación de diminutivos } & \multirow{2}{*}{$\begin{array}{l}\text { Resto de } \\
\text { procesos } \\
\text { derivativos }\end{array}$} \\
\hline & & $\begin{array}{l}\text { Misma } \\
\text { representación } \\
\text { morfológica } \\
\end{array}$ & $\begin{array}{l}\text { Diferentes } \\
\text { representaciones } \\
\text { morfológicas }\end{array}$ & \\
\hline $\begin{array}{l}\text { Mismo } \\
\text { esquema } \\
\text { flexivo }\end{array}$ & $\begin{array}{l}\text { niñ-os/ } \\
\text { cosm-os/ } \\
\text { tes-is/ } \\
\text { brind-is } \\
\text { lun-es/ } \\
\text { vir-us }\end{array}$ & $\begin{array}{l}\text {.niñ-os/cosm- } \\
\text { os } \\
\text { niñ-itos/ } \\
\text { cosm-itos } \\
\text {.manís- } \\
\text { panamás } \\
\text { mani-citos/ } \\
\text { panamá-citos } \\
\text {.lun-es/tes-is } \\
\text { lun-ecito(s)/ } \\
\text { tes-ecita(s) }\end{array}$ & $\begin{array}{l}\text {.cosm-os/tes-is/ } \\
\text { vir-us/brind-is } \\
\text { cosm-itos/tes- } \\
\text { ecita/virus-ito/ } \\
\text { brindis-ito } \\
\text {.trib-us } \\
\text { tribu-cita trib- } \\
\text { ita }\end{array}$ & $\begin{array}{l}\text { niñ-os/cosm- } \\
\text { os/tes-is/vir-us } \\
\text { niñ-ero/cósm- } \\
\text { ico/vir-al/ } \\
\text { tes-ista }\end{array}$ \\
\hline $\begin{array}{l}\text { Diferentes } \\
\text { esquemas } \\
\text { flexivos }\end{array}$ & $\begin{array}{l}\text { man- } \\
\text { ís maní- } \\
\text { es/albal- } \\
\text { ás albalá- } \\
\text { es }\end{array}$ & $\begin{array}{l}\text { maní-es/man- } \\
\text { ís/papá-s/ } \\
\text { trib-us } \\
\text { mani-cito(s)/ } \\
\text { papa-(c)ito(s)/ } \\
\text { tribu-cita(s) }\end{array}$ & $\begin{array}{l}\text { papá-s/pap-as } \\
\text { papa-(c)ito(s)/ } \\
\operatorname{pap-ita(s)}\end{array}$ & $\begin{array}{l}\text { niñ-os/cosm- } \\
\text { os/tes-is/vir- } \\
\text { us/Panamá/ } \\
\text { trib-u/ } \\
\text { manís maní- } \\
\text { es/albal- } \\
\text { ás albalá-es/ } \\
\text { Alcalá } \\
\text { niñ-ero/cósm- } \\
\text { ico/vir-al/tes- } \\
\text { ista/panam- } \\
\text { eño/trib-al/ } \\
\text { mani-sero/ } \\
\text { albala-ero/ } \\
\text { alcala-eño }\end{array}$ \\
\hline
\end{tabular}


Como se puede observar en la primera fila, formas nominales que se ajustan a un mismo esquema flexivo pueden comportarse de la misma manera en todos los procesos derivativos $y$, correlativamente, tener una misma o una única representación morfológica, como es el caso con pares del tipo de niños/cosmos, o bien pueden presentar un comportamiento dispar en la formación de diminutivos, pero no así en el resto de procesos derivativos, como muestran los datos de las dos últimas columnas. Series como la que incluye cosmos, tesis y virus ejemplifican esta situación, mientras que pares del tipo de Panamá/Alcalá plasmarían la situación inversa. Asimismo, formas que difieren en su estructura flexiva pueden sin embargo tener una misma representación morfológica, como muestran en la segunda fila pares del tipo de manílman-í tanto en la formación de diminutivos como en el resto de procesos derivativos, a diferencia de lo que se observa con bases del tipo de lectora o, como sería de esperar, comportarse de manera diferente, como en el caso de niños y manís. Entre los extremos que marcan formas como niños y cosmos por un lado y, por otro, sustantivos del tipo de brindis, crisis y virus, por ejemplo, encontramos muchos nombres que, debido a su patrón acentual, la naturaleza de su vocal (pre)final o a ambos factores, presentan un comportamiento menos uniforme en los diversos procesos derivativos. Como intentamos mostrar en (6), cabe asociar esa variabilidad al hecho de que estas formas se prestan a representaciones morfológicas que pueden diferir de acuerdo con el proceso morfológico considerado. 


\section{Conclusión}

Las observaciones aducidas a lo largo de estas páginas sugieren que las formas nominales del español se agrupan en dos tipos básicos según el comportamiento que presentan, de manera característica, en procesos flexivos y derivativos. El primer grupo incluye aquellas formas que se comportan de manera uniforme en todos los procesos morfológicos y, por consiguiente, tienen una única representación morfológica, en el sentido de que se produce una simetría estricta entre su estructura flexiva y la representación que reciben en los diversos procesos morfológicos (cf. atlas, niños, cosmos). Las formas del segundo tipo se caracterizan por la heterogeneidad de su comportamiento en diversos procesos morfológicos, que está en correlación con la diversidad de las representaciones que reciben, como pone de manifiesto el cotejo de las tres últimas columnas en (6). Debido a esta diferencia, el valor diagnóstico y explicativo de los procesos morfológicos solo puede ser relativo, sobre todo si se establece de manera aislada. Hemos sugerido que en el caso de las formas que tienen variantes morfológicas, la selección de estas últimas descansa en consideraciones morfológicas $\mathrm{y}$, por consiguiente, es independiente de aquellos procesos morfofonológicos cuyo efecto es el borrado de la vocal o la secuencia - Vs final de la base derivativa. Como muestran las formas nominales que no admiten la marca de plural, la estructura de los sustantivos españoles se puede prestar a diferentes interpretaciones, dependiendo del afijo que se les adjunta y del proceso en el que están implicadas. 
Esta variabilidad no se puede disociar de la peculiaridad característica de las formas nominales, en comparación con las verbales, por ejemplo. Si bien la configuración de aquellas se ajusta al esquema flexivo presentado en (1), no todos sus segmentos finales marcan el género ni, en su caso, el número, aun cuando ocupan las casillas que corresponden a las marcas de género y número en las formas regulares. Por otro lado, esa variabilidad está sujeta a una escala asociada a la naturaleza de los segmentos finales, cuya canonicidad incide en la interpretación de la estructura de las piezas léxicas en las que quedan incluidos, en función del proceso considerado y del afijo implicado, como hemos visto. Esta escala da cuenta de las diferencias que se observan entre formas del tipo de cosmos y atlas y otras como crisis, lunes, virus, etc. Como hemos señalado, la variabilidad estructural es muy consistente en las formas acabadas en los segmentos vocálicos altos $/ \mathrm{i}, \mathrm{u} /$, más aun si van seguidos de $/ \mathrm{s} /$, y es menor con las vocales que actúan como marcas canónicas de género en español y con /e/. De tener alguna consistencia la descripción que hemos propuesto en estas páginas, pone de manifiesto las limitaciones de los análisis, de orientación formalista o no, que se basan tanto en la 'desmorfologización’ de los segmentos (pre)finales de las formas nominales, al perder de vista que tales segmentos tienen funciones flexivas (Harris, 1991, 1992; Bermúdez-Otero, 2006, 2007; Bonet, 2006), como en la equiparación de dichos segmentos desde un punto de vista funcional, al considerarlos como alomorfos de las marcas de género típicas del español (Mel'čuk, 2013). Mientras que tales propuestas no pueden dar cuenta de todas las diferencias y semejanzas que 
se observan entre las formas nominales, hemos intentado mostrar que una caracterización cabal y consistente de estas requiere el cotejo de dos clases de representaciones, basadas, respectivamente, en el comportamiento que presentan, de manera característica, en procesos flexivos como la formación del plural y en diferentes procesos derivativos. Representaciones del primer tipo están motivadas en el concepto de esquema flexivo, en contraste con las del segundo tipo, estrechamente ligadas a la interpretación que reciben los sustantivos españoles en los diversos procesos derivativos.

\section{Bibliografía}

Alcoba Rueda, Santiago (2013), "Cambios de acento en español”, Verba, 40, pp. 415-452.

Ambadiang, Théophile (1993), La morfología flexiva, Madrid, Taurus.

Ambadiang, Théophile (1997), "Las bases morfológicas de la formación de diminutivos en español", Verba, 24, pp. 99-132.

Ambadiang, Théophile (1999), “La flexión nominal. Género y número", en Ignacio Bosque y Violeta Demonte (dirs.), Gramática descriptiva de la lengua española, Madrid, Espasa Calpe, pp. 4843-4916.

Ambadiang, Théophile (2011), “Configuración y representación en la flexión nominal: la relevancia de las variaciones morfofonológicas", en M. Victoria Escandell Vidal, M. Leonetti y Cristina Sánchez López (eds.), 
60 problemas de gramática dedicados a Ignacio Bosque, Madrid, AKAL, pp. 349-355.

Ambadiang, Théophile (2015), "Word structure and 'morphological idioms"' ( Ms.).

Baković, Eric (2016), "Exceptionality in Spanish stress", Catalan Journal of Linguistics, 15, pp. 9-25.

Bello, Andrés [1835] (1859), Principios de ortología y métrica de la lengua castellana, y Apéndices, en Obras completas ( $3^{\mathrm{a}}$ ed.), Opúsculos gramaticales, I. Madrid, Manuel Tello, 1890.

Bermúdez Otero, Ricardo (2006), "Morphological structure and phonological domains in Spanish denominal derivation", en Fernando Martínez-Gil y Sonia Colina (eds.), Optimality-theoreticstudies in Spanishphonology, Ámsterdam/Filadelfia, John Benjamins, pp. 278-311. Bermúdez Otero, Ricardo (2007), "Spanish pseudoplurals: phonological cues in the acquisition of a syntax-morphology mismatch", en Matthew Baerman, Greville Corbett, Dunstan Brown y Andrew Hippisley (eds.), Deponency and morphological mismatches (Proceedings of the British Academy), Oxford, Oxford University Press, pp. 231-269.

Bonet, Eulalia (2006), "Gender allomorphy and epenthesis in Spanish", en Fernando Martínez-Gil y Sonia Colina (eds.), Optimality-Theoretic Studies in Spanish Phonology, Ámsterdam/Filadelfia, John Benjamins, pp. 312328.

HARRIS, JAMES W. (1983), Syllable structure and stress in Spanish. A nonlinear analysis, Cambridge, Mass., MIT Press. 
HARRIs, JAMES W. (1991), “The exponence of gender in Spanish", Linguistic Inquiry, 22, pp. 27-62.

Harris, James W. (1992), "The form classes of Spanish substantives", en Yearbook of Morphology 1991, Dordrecht, Kluwer, pp. 65-88.

HARRIS, JAMES W. (1994), "Projection and edge marking in the computation of stress in Spanish", en John Goldsmith (ed.), Handbook of Phonological Theory, Oxford, Basil Blackwell, pp. 867-887.

Hooper, Joan y Tracy Terrell (1976), "Stress assignment in Spanish: A natural generative analysis", Glossa, 10, pp. 64-110.

Lázaro Mora, Fernando A. (1999), "La derivación apreciativa", en Ignacio Bosque y Violeta Demonte (dirs.), Gramática descriptiva de la lengua española, Madrid, Espasa-Calpe, pp. 4645-4682.

Lloret, Maria-Rosa (2013), "Diferències en les terminacions flexives dels elements nominals", en Esteve Clua y Rosa-Maria Lloret (eds.), Qüestions de morfología flexiva i léxica del català. Volum d'homenatge a Joaquim Viaplana, Alicante, Institut Interuniversitari de Filologia Valenciana, pp. 245-278.

Lloret, Maria-Rosa y Joaquim Viaplana (1998), "El binarismo del género gramatical en castellano y en catalán", Verba, 25, pp. 71-91.

Mel'čuk, I. (2013), "The notion of inflection and the expression of nominal gender in Spanish", Studies in Language, 37, 4, pp. 736-763.

Montermini, Fabio (2011), "Suffixation et voyelles finales en italien", en B. Fradin, G. Dal, N. Hathout, F. Ker- 
leroux, M. Plénat y M. Roché (eds.), Silexicales 3. Les unités morphologiques, pp. 133-141.

Pensado, Carmen (1999), “Morfología y fonología. Fenómenos morfofonológicos", en Ignacio Bosque y Violeta Demonte (dirs.), Gramática descriptiva de la lengua española, Madrid, Espasa Calpe, pp. 4423-4504.

RAE-ASALE [Real Academia Española-Asociación de Academias de Lengua Española] (2009), Nueva gramática de la lengua española, Madrid, Espasa Calpe.

RocA, IGGy (1988), "Theoretical implications of Spanish word stress", Linguistic Inquiry, 19, pp. 393-423.

RocA, IGGY (1989), "The organisation of the Spanish gender", Transactions of the Philological Society, 87, 1, pp.132.

RocA, IGGY (1990), "Diachrony and synchrony in word stress", Journal of Linguistics, 26, 1, pp. 133-164.

RocA, IgGy (2006), “The Spanish stress window”, en Fernando Martínez-Gil y Sonia Colina (eds.), Optimality-Theoretic Studies in Spanish Phonology, Ámsterdam, John Benjamins, pp. 239-277.

Roca, Iggy y Elena Feliú (2002), "Morphology in truncation: the role of the Spanish desinence", en Yearbook of Morphology 2002, Ámsterdam, Kluwer, pp. 187-243. 